\title{
The Pharmaceutical and Antimicrobial Properties of Dermatological Formulations Containing Hyptis Suaveolens (L.) Poit (Lamiaceae) Aerial Extract
}

\author{
Olusola I. Aremu1 ${ }^{1,2}$, Tolulope 0. Ajala ${ }^{3}$, Isaac J. Ajeh ${ }^{1}$, Kokonne E. Ekere ${ }^{1}$ \\ 1Department of Pharmaceutical Technology and Raw Materials Development, National Institute \\ for Pharmaceutical Research and Development, Abuja, Nigeria. \\ 2 Department of Pharmaceutics and Industrial Pharmacy, Faculty of Pharmaceutical Sciences, \\ University of Ilorin, Kwara State, Nigeria. \\ 3Department of Pharmaceutics and Industrial Pharmacy, Faculty of Pharmacy, University of \\ Ibadan, Oyo State, Nigeria
}

\begin{abstract}
The plant Hyptis suaveolens (L.) Poit (Lamiaceae) has received a lot of recognition because of its ethno-medicinal claims, some of which have been justified by scientific studies. The intention of this present work was to develop an antimicrobial dermatological dosage formulation. The powdered aerial extract was macerated in methanol for $72 \mathrm{~h}$ and the extract was formulated using vanishing cream base as vehicle at concentrations of $2.5,5.0$ and $7.5 \% \mathrm{w} / \mathrm{w}$ respectively. The formulations were tested against selected microorganisms such as Staphylococcus aureus, Pseudomonas aeruginosa (Clinical isolates and standard strains), Trichophyton rubrum and Candida albicans. The results showed that activities against bacterial clinical isolates were not as encouraging as that of standard strains, while exhibiting significant concentration dependent antifungal activity $(\mathrm{p}<0.05)$ against the microorganisms tested with. This therefore shows potential for development as a standardized dosage form for the treatment of skin infections where the interrogated microorganisms are implicated.
\end{abstract}

Keywords: Hyptis suaveolens, Aerial extract, Dermatological formulations, Antimicrobial properties.

\footnotetext{
*Corresponding Author: Olusola I. Aremu, e-mail: solabank@yahoo.com Olusola I. Aremu ORCID Number: 0000-0002-3890-1256 Tolulope 0. Ajala ORCID Number: 0000-0002-1257-746X Isaac J. Ajeh ORCID Number: 0000-0003-3931-9521 Kokonne E. Ekere ORCID Number: 0000-0001-8876-9284 (Received 18 April 2019, accepted 20 May 2019)
} 


\section{INTRODUCTION}

Herbal preparations are believed to contain ingredients that are active alongside many other substances. Currently, medicines derived from plants are being developed by many drug industries due to a wide spread perception that they are more effective, less toxic, less expensive and more reliable than the synthetic ones ${ }^{1}$. World Health Organization has also indicated readiness in promoting the development and use of herbal medicines especially in third world countries. Works by scientists are on-going in search for ingredients that are active biologically and have low side effect profile, though natural products as antibacterial agents have long been evaluated ${ }^{2}$. Higher plants are rich in secondary metabolites and are very good sources of antimicrobial compounds. Pharmacological characters in these metabolites have been utilized to arrest and destroy disease-causing pathogens.

Currently, infectious diseases are still a major cause of mortality and disability globally. As infection is increasing, resistance against antibiotics is also increasing. Resistance to synthetic antibiotics is worrisome.

Hyptis suaveolens (L.) Poit is also known as pignut, bush mint, horehound, wild spikenard and a variety of names in French, Portuguese, Spanish and Hindi ${ }^{3}$. It is a plant which is usually known as a weed with a variety of medicinal and food uses cultivated in India and Mexico. It is a small erect plant usually about $2.5 \mathrm{~m}$ in height with woody, hairy stem ${ }^{4}$. It is a plant belonging to the family Lamiaceae. It is basically considered an obnoxious weed and widely distributed throughout the tropics and subtropics ${ }^{4}$. Almost every part of the plant has been reported to have medicinal properties. This plant is known for its strong smell which confers on it its insecticidal properties. It produces flowers and seeds in abundance annually which make it a good candidate for pollination ${ }^{5}$. It contains alkaloids, phenols, saponins and most importantly essential oils. The essential oil can be obtained from the leaves, shoots and roots; however, the composition of the oils will vary based on geographical location at any point in time ${ }^{6}$.

The seeds of the plant are used as a drink or for food in some parts of the world while the shoots and leaves are used as flavoring and tea respectively ${ }^{7}$. Medicinally, the roots are used as an appetizer while the whole plant part is useful for dermatological infections, headaches, fevers and malaria ${ }^{7}$. Its essential oil finds application in infections and inflammatory conditions and as an insect repellent against mosquitoes ${ }^{8}$. The essential oil obtained from the leaves has shown potential as an antibacterial agent against gram positive and gramnegative bacteria most especially Staphylococcus aureus, Escherichia coli and Pseudomonas aeruginosa etc. In addition, the essential oil from the leaves has 
shown good antifungal activity compared to the standard antifungal, ketocona$z^{2} e^{6}$. The anti-inflammatory activity of components of the essential oil, suaveolol and methyl suaveolate has also been studied and its effect was similar to ibuprofen, a standard anti-inflammatory agent. Interestingly, its antiplasmodial activity has been studied showing activity against chloroquine resistant and sensitive Plasmodium falciparum. The component responsible for this activity is dehydroabietinol ${ }^{9}$.This present study involves the preparation and evaluation of an herbal skin care formulation for antimicrobial action against selected microorganisms which are associated with localized skin infections. The cream formulation consists of the methanol extract of Hyptis suaveolens (aerial) and this herb has been selected based on the scientific justification of its properties.

\section{METHODOLOGY}

Materials used were Methanol (Merck KGaA 64271 Darmstadt Germany), Stearic acid, Glycerin monostearate, Cetyl alcohol, Potassium hydroxide (Allied Chemicals Ltd, England), Methyl paraben, Propyl paraben (Clariant, UK), Distilled water (National Institute for Pharmaceutical Research and Development, Nigeria).

\section{Plant collection}

Hyptis suaveolens (aerial) was collected on $31^{\text {st }}$ January 2019 from Idu industrial area of Abuja Municipal Area Council of Nigeria. It was identified and given a voucher number (NIPRD/H/702O) and air dried at room temperature for 5 days at the Department of Pharmaceutical Technology and Raw Materials Development, National Institute for Pharmaceutical Research and Development (NIPRD).

\section{Preparation of crude extract}

The dried aerial parts were pulverized using mortar and pestle. It was then sieved using sieve size $600 \mu \mathrm{m}$. An amount (500 g) of the sieved powder was poured into a bowl and 2.5 $\mathrm{L}$ of methanol was added to it, covered and allowed to stand for $72 \mathrm{~h}$. It was then decanted and filtered using a Whatman No 1 filter paper and the filtrate was concentrated on a water bath at $40{ }^{\circ} \mathrm{C}$. It was air dried, pulverized and the yield was calculated.

\section{Formulation of creams}

The oil phase was prepared by weighing $13 \mathrm{~g}$ of stearic acid, $1 \mathrm{~g}$ of glycerin monostearate and $1 \mathrm{~g}$ of cetyl alcohol into a beaker. The beaker was then heated on a water bath to $70{ }^{\circ} \mathrm{C}$. The aqueous phase was prepared by weighing $10 \mathrm{~g}$ of glycerin and $0.9 \mathrm{~g}$ of potassium hydroxide into another beaker, $0.1 \mathrm{~g}$ of methyl paraben and $0.05 \mathrm{~g}$ of propyl paraben were also added as preservatives. Suffi- 
cient amount of water (73.95 g) was added to make up to $100 \mathrm{~g}$ and the mixture heated to $75{ }^{\circ} \mathrm{C}$. The oily phase was added to the aqueous phase, vigorously stirred together until the pre-emulsion was formed. Thereafter, appropriate quantities of the extract were incorporated to make 0.0, 2.5, 5.0 and 7.5\%w/w concentrations. Later, the emulsion was transferred into a porcelain mortar and then triturated with a pestle for globule size reduction and smoother emulsion.

\section{Physical evaluations}

The appearance, colour, odour, texture, ease of removal, homogeneity and phase separation of the different concentrations of the creams prepared were observed and recorded.

\section{Viscosity}

The viscosity of the formulation was carried out using a Brookfield viscometer (VT 181, Karlsruhe, Germany) at $27 \pm 2{ }^{\circ} \mathrm{C}$ using spindle number seven and the rotational speed of 0.5 to $100 \mathrm{rpm}$. The shear stress was determined by calculation and appropriate plots were made.

\section{pH determination}

The $\mathrm{pH}$ of the prepared creams was determined using a $\mathrm{pH}$ meter (Jenway 3505 ) in triplicate and result expressed as mean $\pm \mathrm{SD}$.

\section{Occlusion properties}

Each cream formulation (200 mg) was carefully weighed on a filter paper and evenly spread out. This was then placed on a clean sample bottle having 2.3 $\mathrm{cm}$ diameter surface. The average perimeter of the filter paper was $22.9 \mathrm{~cm}$. Distilled water $(20 \mathrm{~mL}$ ) was carefully transferred into each bottle and the filter paper containing the spreaded cream was placed on top to cover the entire mouth of the bottle. The water loss was determined at 24-144 h; controls with ordinary filter paper i.e. positive control (CP) and without any filter paper i.e. negative control (CN) were set up as well. Readings were taken every $24 \mathrm{~h}$. Plots of percentage water loss against time were prepared. The occlusion factor (F) was calculated using the equation below:

$F=\frac{A-B}{B} \times 100$

where, $\mathrm{B}$ is the water loss from the test formulations, $\mathrm{A}$ is the water loss of the filter without a sample (blank reference). An occlusion factor of zero indicates no occlusive effect compared with the reference, and 100 was the maximum occlusion factor ${ }^{10}$. 


\section{The globule sizes of the dermatological formulations}

The globule sizes of the internal phase for the dermatological formulations were measured using an optical microscope (Olympus Light Microscope). The microscope was fitted with a camera and computer software-Motic MC 1000 (Motic China Group Co.Ltd.,) for image analysis transmitted on the monitor. The microscopic samples were prepared by spreading a very thin layer of the cream on a specimen slide, stained with crystal violet and spread evenly with the aid of a cover slip. One hundred globules were measured from each preparation and the photomicrographs also documented.

\section{Evaluation of cream Stability}

An accelerated stability study was carried out to check for changes in colour, phase separation and $\mathrm{pH}$ of the different concentrations of the creams at $4{ }^{\circ} \mathrm{C}$, $25^{\circ} \mathrm{C}$ and $40^{\circ} \mathrm{C}$ for 3 months. Samples were placed in the refrigerator, room temperature and photo stability chamber (Model 1810, Vindon Scientific, Germany) set at $40{ }^{\circ} \mathrm{C}$. Samples were withdrawn at monthly interval and checked for changes in colour, phase separation and $\mathrm{pH}$ at day 1 , after 1 month, after 2 months and after 3 months.

\section{Antimicrobial assessment}

The cream formulations were screened for antibacterial activity on Staphylococcus aureus and Pseudomonas aeruginosa using clinical isolates obtained from the Department of Medical Microbiology of the University College Hospital, Ibadan. Standard microorganisms were obtained from the International Centre for Drug Research, Lucknow and used as well. The standard microorganisms used were Staphylococcus aureus ATCC 29213 and Pseudomonas aeruginosa ATCC 27853. Cream formulations were used in diluted (25, 50 and 100 $\mathrm{mg} / \mathrm{mL}$ ) and undiluted form (100 mg). Microorganisms were seeded in Mueller Hinton agar (Merck, Germany) and agar wells $(6 \mathrm{~mm})$ bored after setting. Sterile spatula was used to fill the holes with the cream formulations. Diffusion was allowed to occur for 45 minutes before incubating at $37^{\circ} \mathrm{C}$ for 24 hours. Zones of growth inhibition were measured in millimetres. Control experiments were done using distilled sterile water and Betamethasone-neomycin cream. All experiments were done in triplicate and results presented as mean $\pm \mathrm{SD}$.

The antifungal activity of the cream formulations was assessed using Candida albicans and Trichophyton rubrum obtained from the Department of Pharmaceutical Microbiology, Faculty of Pharmacy, University of Ibadan, Ibadan. Cream formulations were used in diluted $(25,50$ and $100 \mathrm{mg} / \mathrm{mL})$ and undiluted form (100 mg). Previously sterilized saboraud dextrose agar $(20 \mathrm{~mL})$ was 
cooled to $45^{\circ} \mathrm{C}$ and poured into sterile petri dishes. After the agar has set, about $0.2 \mathrm{~mL}$ of a 24-hour old culture of the fungal isolates in nutrient broth was streaked unto the agar. Holes were bored with sterile cork borer of $6 \mathrm{~mm}$ and a sterile spatula was used to fill the holes with the cream formulations. Diffusion was allowed to occur for 45 minutes before incubating at $25-27^{\circ} \mathrm{C}$ for a minimum of 48 hours. Zones of growth inhibition were measured in millimetres. Control experiments were set up using distilled sterile water and ketoconazole cream. All experiments were done in triplicate and results presented as mean $\pm \mathrm{SD}$.

\section{RESULTS AND DISCUSSION}

A limiting factor to most medicinal plants for managing disease conditions is the form in which they are presented ${ }^{11}$. In this study, extracts from the aerial part of Hyptis suaveolens was used to formulate various concentrations of oilin-water emulsion cream that can be used in the treatment of various skin diseases (Table 1).

\section{Organoleptic properties}

The extract from Hyptis plant was dark green with a characteristic pungent and sharp smell. Creams formulated with various concentrations of Hyptis suaveolens aerial extract were army green in colour with degree of sharpness of odour increasing as concentration increases. Suitable colourant may enhance its elegance and acceptability. All the creams prepared were easily removed with water, this is an advantage because patients comply easily with nongreasy, non-occlusive, easily washable dermal preparations. This also means that the density of the particles in the formulations are proportionate to that of the cream base ${ }^{12}$. All creams formulated were non-irritating when applied to the skin after a period of 8 hours, with a soft and smooth feeling. There was no extract-vehicle incompatibility observed. Phase separation was not noticed in any of the formulations even after 3 months at 4,25 and $40{ }^{\circ} \mathrm{C}$ respectively. This implies that the difference in density of the extract to that of the base is insignificant ${ }^{13}$ and that the formulation will be able to withstand different storage conditions without losing their structural integrity.

\section{pH}

The $\mathrm{pH}$ of a medium, measures the acidity or alkalinity of a phase. A slight difference in $\mathrm{pH}$ of a product can affect how a formulation interacts with the skin ${ }^{14}$. The literature reports the $\mathrm{pH}$ of the skin to be between $5 \cdot 4-5 \cdot 9^{14}$. It is therefore necessary that the base chosen should have desirable characteristic including an acceptable $\mathrm{pH}$. The $\mathrm{pH}$ of the creams formulated was in the range of 6-7 at 
the point of preparation. After exposure to different storage conditions (4, 25 and $40^{\circ} \mathrm{C}$ ) for 3 months, changes in $\mathrm{pH}$ were not significant ( $\left.\mathrm{p}>0.05\right)$ as they were still within the range as that of baseline (Figure 1-3). Changes in $\mathrm{pH}$ may be a signal to chemical decomposition, most probably of a hydrolytic nature, and if detected, could be a reason to return a product ${ }^{15}$.

Table 1. Composition of the Hyptis suaveolens herbal cream formulations

\begin{tabular}{|lcccc|}
\hline \multicolumn{1}{c}{ Ingredients } & A1 & B1 & C1 & D1 \\
\hline Stearic acid $\mathbf{( g )}$ & 13.00 & 13.00 & 13.00 & 13.00 \\
Glycerin monostearate $\mathbf{( g )}$ & 1.00 & 1.00 & 1.00 & 1.00 \\
Cetyl alcohol $\mathbf{( g )}$ & 1.00 & 1.00 & 1.00 & 1.00 \\
Glycerin $(\mathbf{g})$ & 10.00 & 10.00 & 10.00 & 10.00 \\
Potassium hydroxide $\mathbf{( g )}$ & 0.90 & 0.90 & 0.90 & 0.90 \\
Methyl paraben $\mathbf{( g )}$ & 0.10 & 0.10 & 0.10 & 0.10 \\
Propyl paraben $\mathbf{( g )}$ & 0.05 & 0.05 & 0.05 & 0.05 \\
Extract $\mathbf{( g )}$ & 0.00 & 2.50 & 5.00 & 7.50 \\
Water $\mathbf{( g )}$ & 73.95 & 71.45 & 68.95 & 66.45 \\
\hline Total weight $\mathbf{( g )}$ & 100.00 & 100.00 & 100.00 & 100.00 \\
\hline
\end{tabular}

A1, B1, C1 and D1 are 0.0, 2.5, 5.0 and 7.5 \% w/ respectively of Hyptis suaveolens dermatological formulations.

Table 2. Organoleptic properties of the extract and creams at baseline and after 1, 2 and 3 months at $4{ }^{\circ} \mathrm{C}, 25^{\circ} \mathrm{C}$ and $40^{\circ} \mathrm{C}$.

\begin{tabular}{|c|c|c|c|c|}
\hline & Colour & Odour & \multicolumn{2}{|c|}{ Texture } \\
\hline Hyptis extract & Dark green & $\begin{array}{l}\text { Pungent and } \\
\text { sharp }\end{array}$ & \multicolumn{2}{|c|}{ Fine } \\
\hline $\begin{array}{l}\text { Properties of } \\
\text { cream }\end{array}$ & A1 & B1 & C1 & D1 \\
\hline Appearance & Smooth & Smooth & Smooth & Smooth \\
\hline Colour & White & Army green & Army green & Army green \\
\hline Odour & Odourless & Pungent & Pungent & Pungent \\
\hline Texture & Smooth and soft & Smooth and soft & Smooth and soft & Smooth and soft \\
\hline $\begin{array}{c}\text { Ease of } \\
\text { application }\end{array}$ & $\begin{array}{l}\text { Easy to apply on } \\
\text { rubbing }\end{array}$ & $\begin{array}{l}\text { Easy to apply on } \\
\text { rubbing }\end{array}$ & $\begin{array}{l}\text { Easy to apply on } \\
\text { rubbing }\end{array}$ & $\begin{array}{l}\text { Easy to apply on } \\
\text { rubbing }\end{array}$ \\
\hline Skin irritation & Non irritant & Non irritant & Non irritant & Non irritant \\
\hline
\end{tabular}


Table 3. The occlusion factor and globule sizes of Hyptis suaveolens dermatological formulations

\begin{tabular}{|c|c|c|c|}
\hline Formulation code & $\begin{array}{c}\text { Occlusion Factor, } \\
\mathbf{F}(\boldsymbol{\%})\end{array}$ & Remark & Globule size $(\boldsymbol{\mu} \boldsymbol{m})$ \\
\hline A1 & 41.18 & Fairly occlusive & $25.60 \pm 23.12$ \\
B1 & 41.18 & Fairly occlusive & $23.79 \pm 9.93$ \\
C1 & 41.18 & Fairly occlusive & $31.64 \pm 14.16$ \\
D1 & 70.59 & Moderately & $33.24 \pm 10.52$ \\
\hline
\end{tabular}

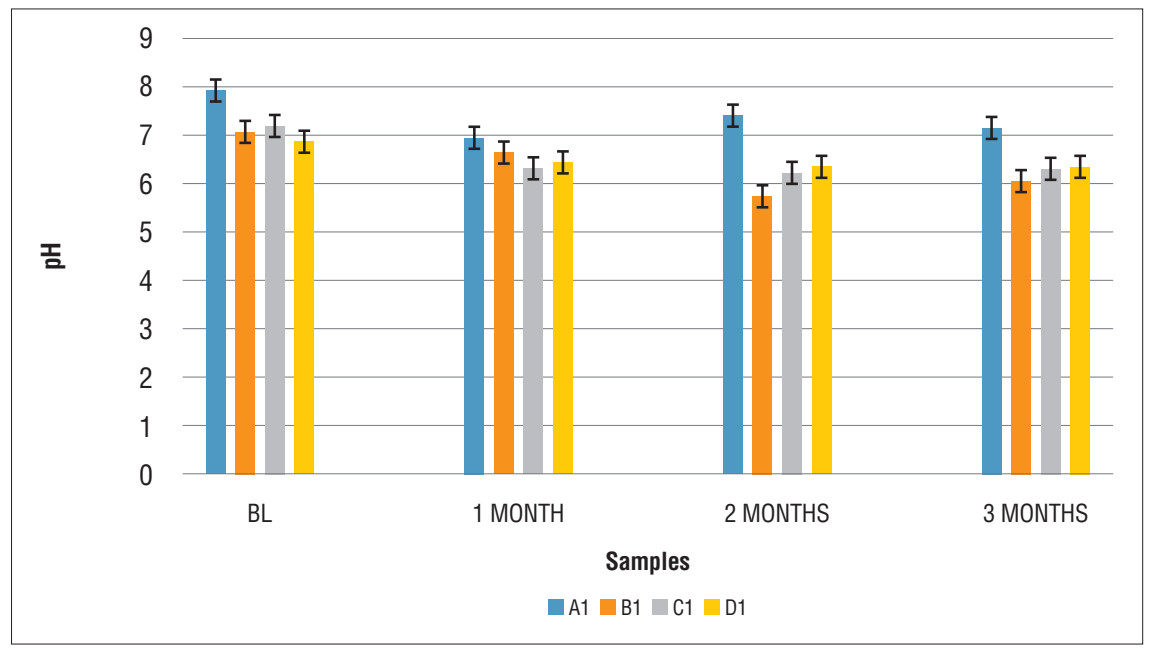

A1, B1, C1 and D1 are 0.0, 2.5, 5.0 and $7.5 \%$ w/w respectively of Hyptis suaveolens herbal cream. formulations.

Figure 1. $\mathrm{pH}$ of the creams at baseline (BL), after 1,2 and 3 months at $4{ }^{\circ} \mathrm{C}$. 


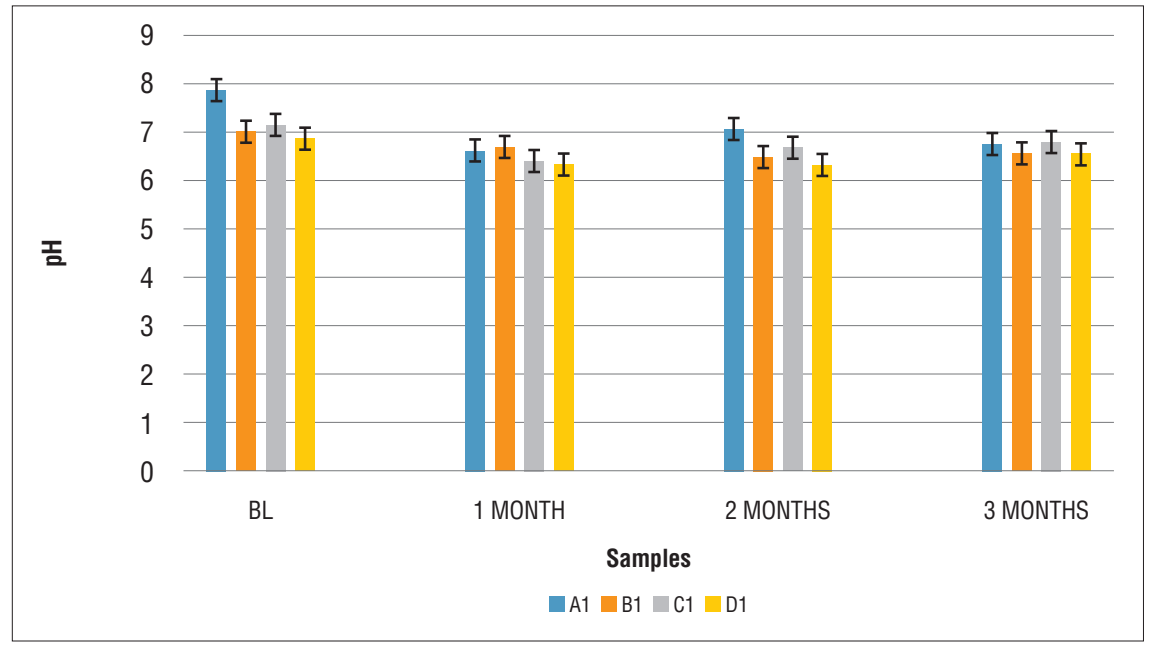

A1, B1, C1 and D1 are 0.0, 2.5, 5.0, and 7.5\% \% ${ }_{\text {w }}$ of Hyptis suaveolens aerial extract cream respectively

Figure 2. $\mathrm{pH}$ of the creams at Baseline (BL), after 1, 2 and 3 months at $25^{\circ} \mathrm{C}$

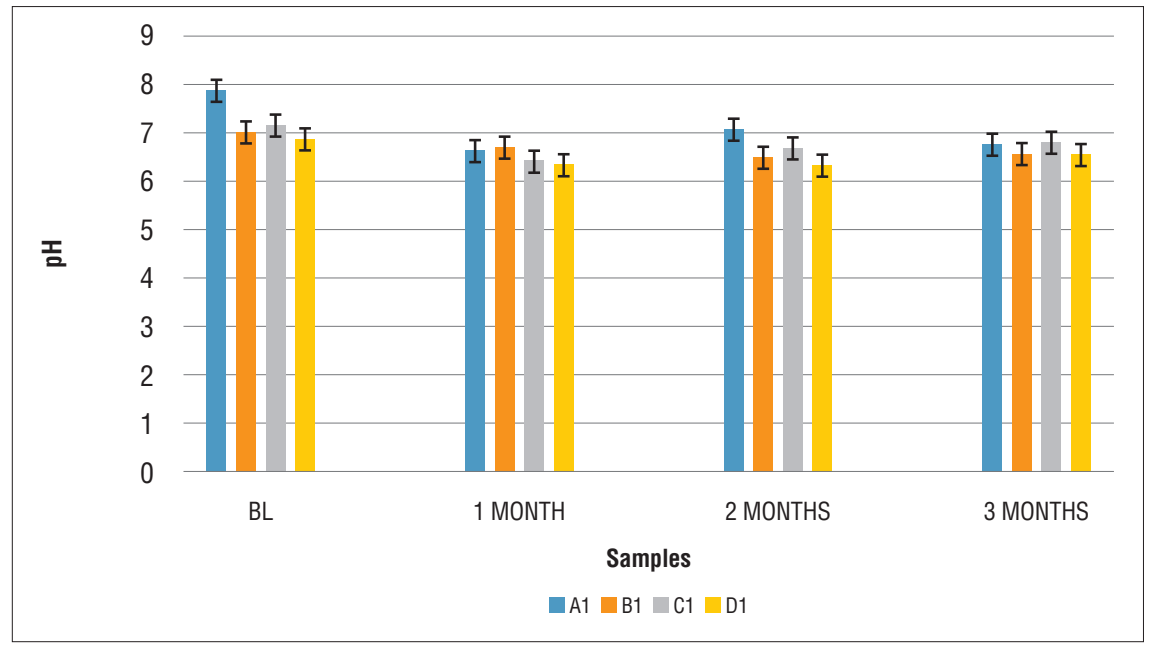

A1, B1, C1 and D1 are 0.0, 2.5, 5.0, and 7.5\% \% $/$ w of Hyptis suaveolens aerial extract cream respectively

Figure 2. $\mathrm{pH}$ of the creams at Baseline (BL), after 1,2 and 3 months at $25^{\circ} \mathrm{C}$ 


\section{Viscosity}

The cream formulations generally had high viscosity values thus reflecting the adherence property of semi-solid pharmaceutical dosage forms and the high yield stress involved such that it will not run off the skin surface after application. Yield stress is the minimum stress that must be applied before a material starts to flow ${ }^{16}$. The yield stress of cream formulations should be high enough so that they do not flow out of their container due to their own weight if the container is placed in an upside-down position. It should however not be too high to offer significant resistance during application onto the skin. In terms of viscosity values, the cream formulations are acceptable.

As shown in Figure 4, formulations A1, C1 \& D1 exhibited reduced viscosity with increased shear stress, while the viscosity of $\mathrm{B} 1$, seem not to depend on shear stress as it increased irrespective of the force applied. Generally, semisolid formulations undergo a wide variety of stress during removal from the container and application to the affected area ${ }^{17}$. Evaluating the effect of stress on the cream is thus important to determine its behaviour during transportation and use.

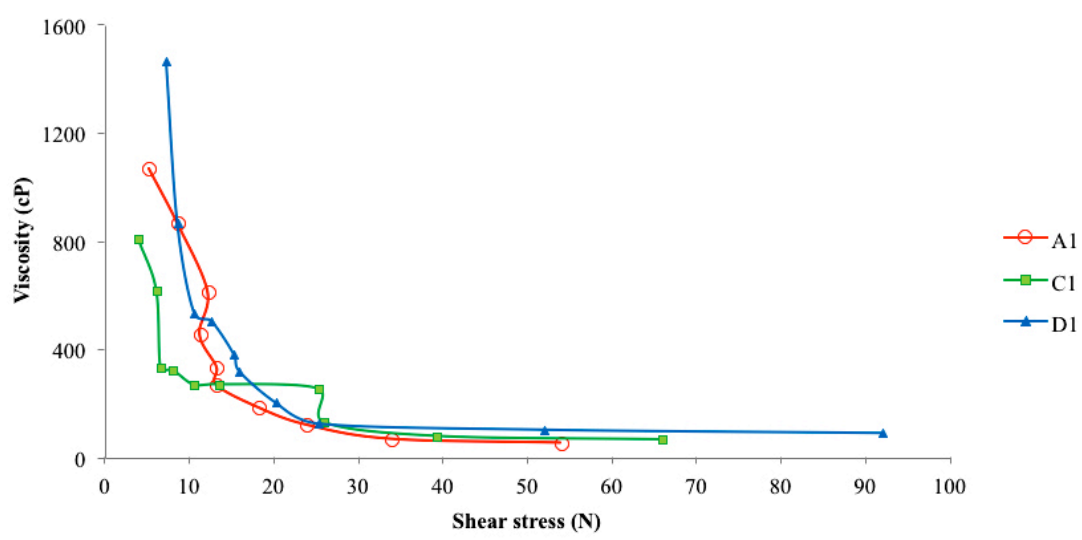




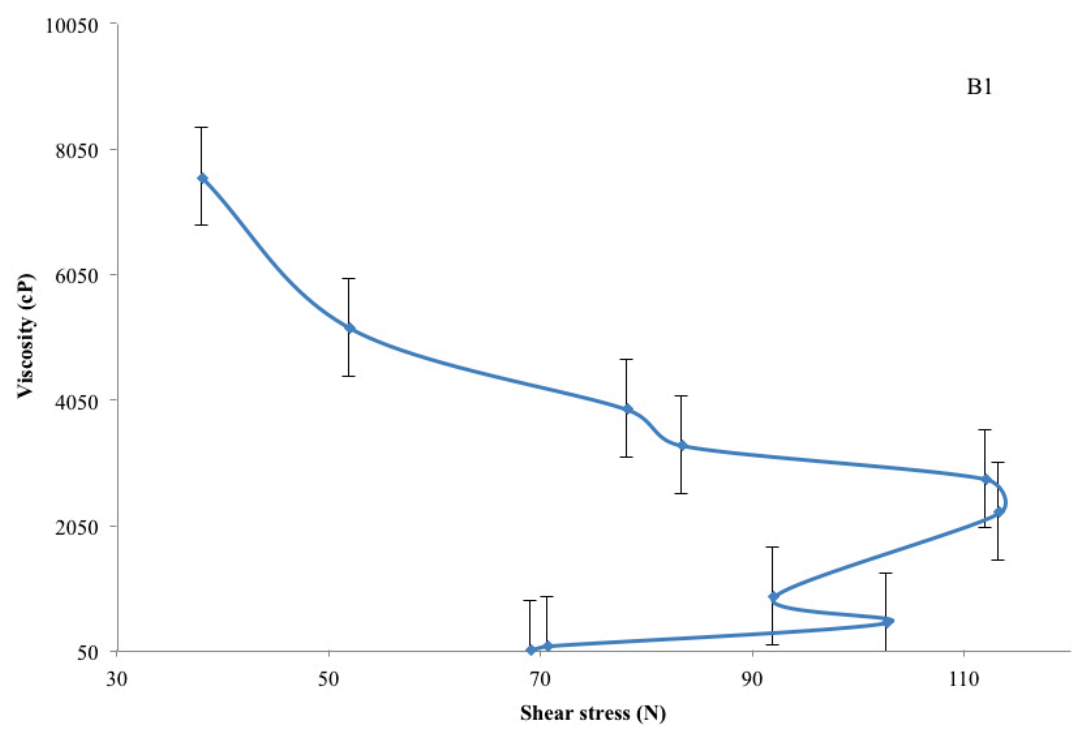

A1, B1, C1 and D1 are 0.0, 2.5, 5.0 and 7.5\% \% $/$ w respectively of Hyptis suaveolens dermatological formulations

Figure 4. The effect of shear stress on the viscosity of Hyptis suaveolens dermatological formulations

In addition, the viscosity of all the cream formulations generally reduced as the rate of shear increased as shown in Figure 5. The cream formulations therefore demonstrated pseudoplastic rheological pattern. Due to the peculiar rheological behaviour of semisolids, they can adhere to the skin or mucous membrane for sufficiently long periods before they are washed off. The viscosity of a semi solid formulation is the adherent property that enables it to cling as films until an external force act on it. This property enables semi-solid formulations to exhibit prolonged activity on the skin ${ }^{17}$. 

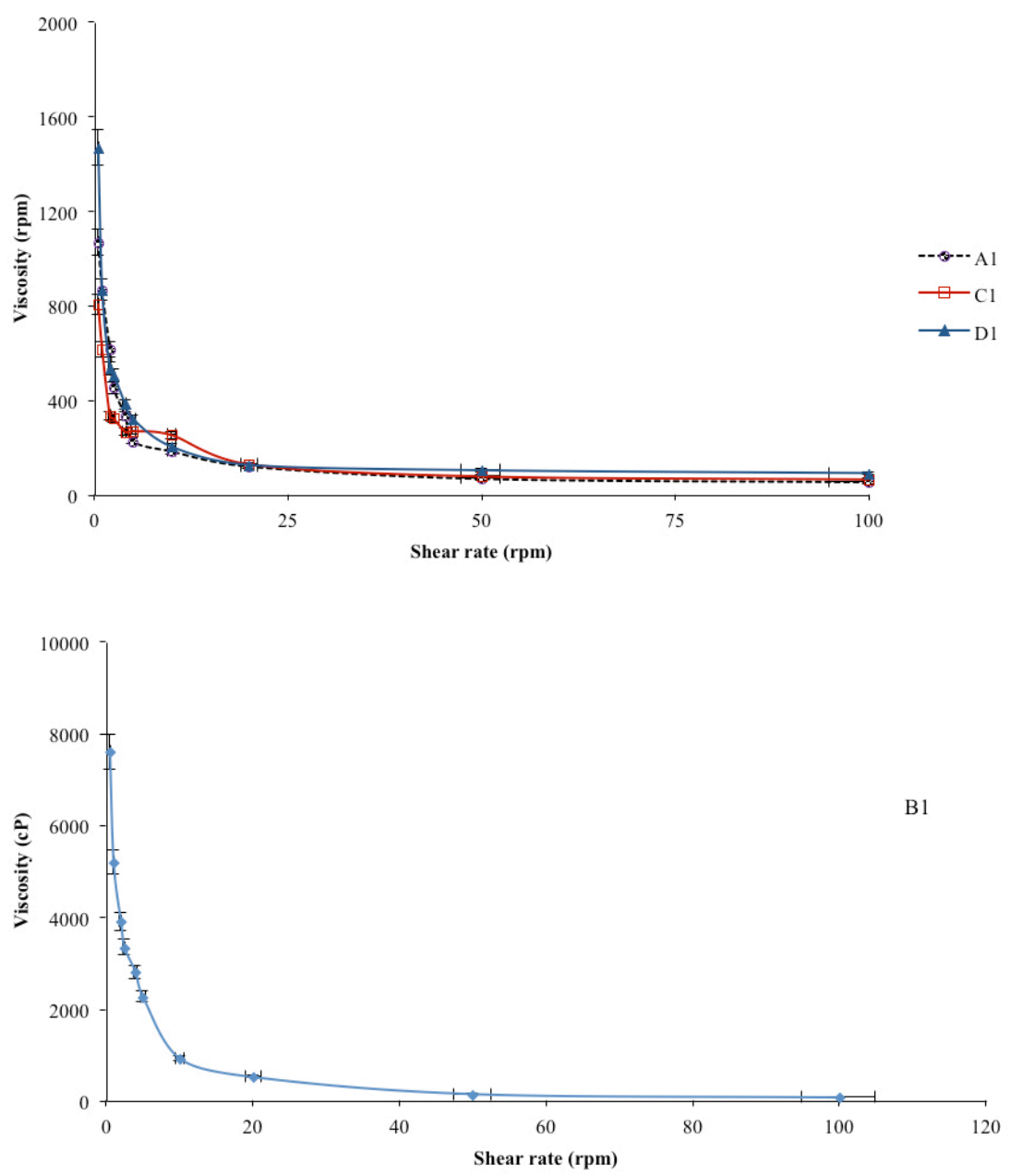

A1, B1, C1 and D1 are 0.0, 2.5, 5.0 and 7.5\% w/w respectively of Hyptis suaveolens dermatological formulations

Figure 5. The effect of shear rate on the viscosity of Hyptis suaveolens dermatological formulations 


\section{Occlusion factor}

The occlusion factor as presented in Table 3 showed that the cream formulations had occlusion properties ranging from fair to very high. When a topical pharmaceutical formulation is occlusive, such products form barrier on the skin and thus affects skin hydration. Occlusive products are usually oil-based semi-solid formulations and such provide skin barrier repair through restoration of lipids in the skin. In addition to the therapeutic activity of these cream formulations, they will also help in preventing skin dryness, maintenance of skin smoothness and elasticity ${ }^{18}$. This assertion will be further strengthened if ex-vivo and in vivo occlusion studies can be done.

\section{Percent loss of water from formulations}

As shown in Figure 6, the negative control lost more water than all the formulations. Generally, the percentage water loss from all the formulations were not up to $10 \%$ even after 144 hours. It shows that the creams probably had significant occlusive properties. This cannot however be ascertained until the occlusion factor (F) is calculated. The cream formulations also had water losses lower than the controls. The filter paper pores were occluded by the cream samples at varying degrees hence the loss of water differs. The formulation ingredients usually affect the properties exhibited by the product. The ranking of percentage water loss was $\mathrm{CN}>\mathrm{CP}>\mathrm{B} 1>\mathrm{A} 1>\mathrm{C} 1>\mathrm{D} 1$. This implies that formulation D1 will retain water more than the others and therefore maintain its physical outlook more than the other with faster tendency of drying up. 


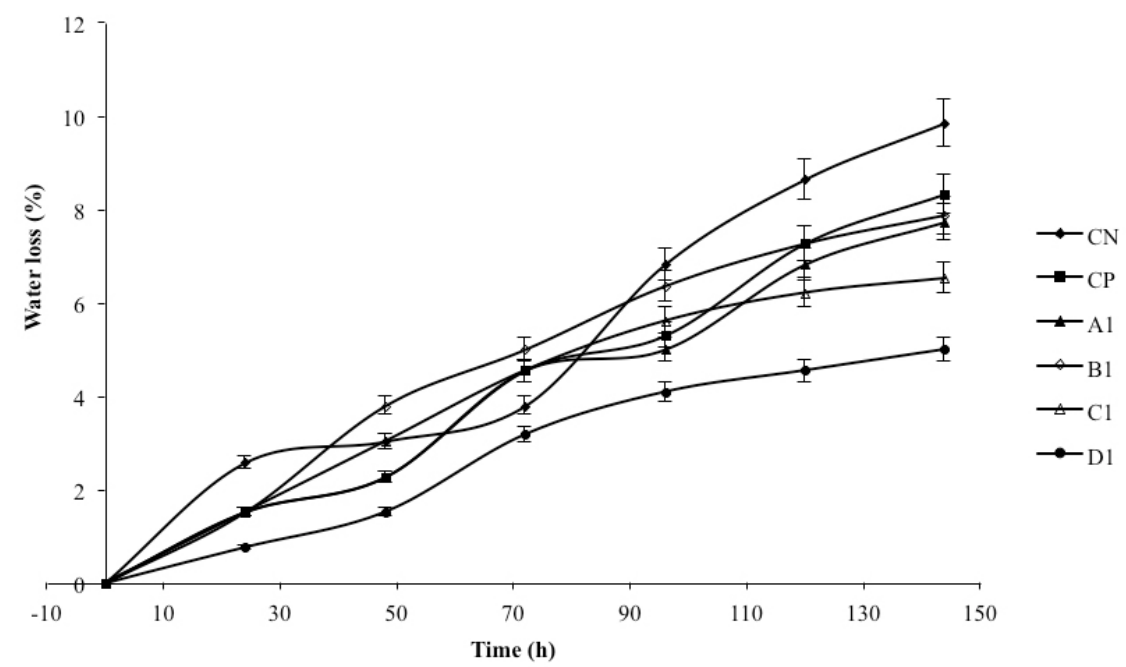

$C N$ and $C P$ are negative and positive controls while $A 1, B 1, C 1$ and $D 1$ are o.o, 2.5, 5.0 and $7.5 \% w / w$ respectively of Hyptis suaveolens dermatological formulations

Figure 6. The effect of time on water loss from Hyptis suaveolens dermatological formulations

\section{Globule size distribution}

The mean globule size of Hyptis suaveolens dermatological formulations are presented in Table 3, while the globule size distributions are in Figure 7. The results showed that the mean globule sizes were between $23.79 \pm 9.93$ to 33.24 $\pm 10.52 \mu \mathrm{m}$. The globule size distribution for all the formulations showed a sigmoidal pattern and least sizes ranged from 2.00-14.78 $\mu \mathrm{m}$ ranking in the order of $\mathrm{C} 1<\mathrm{A} 1<\mathrm{B} 1<\mathrm{D} 1$. The highest sizes also ranged from 52.93-114.90 $\mu \mathrm{m}$ in the order of $\mathrm{B} 1<\mathrm{D} 1<\mathrm{C} 1<\mathrm{A} 1$. Frequency statistics revealed that $75 \%$ of the globules had sizes generally below $41 \mu \mathrm{m}$ while $25 \%$ were lower than $27 \mu \mathrm{m}$. Conventional creams have a mean droplet size ranging from 10 to $100 \mu \mathrm{m}$ and such formulations generally demonstrate poor penetration of drug-loaded oil droplets into deep skin layers ${ }^{19}$. It has also been reported that microparticles with diameters ranging from 3 to $10 \mu \mathrm{m}$ selectively penetrate follicular ducts, whereas particles $>10 \mu \mathrm{m}$ remain on the skin surface, and those $<3 \mu \mathrm{m}$ are distributed randomly into hair follicles and stratum corneum ${ }^{19}$. This implies that the activity of the dermatological formulations prepared in this study will cut across the hair follicles, stratum corneum, follicular ducts and skin surface because of lower and higher sizes of the globules ${ }^{20}$. 


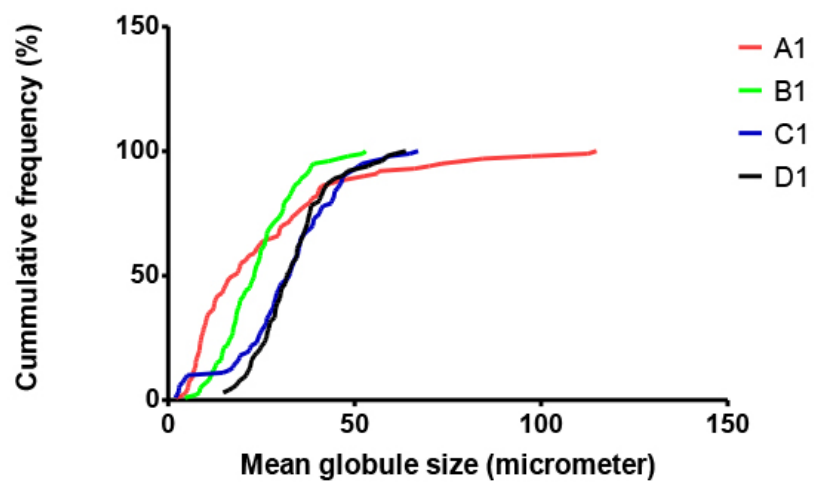

A1, B1, C1 and D1 contains 0.0, 2.5, 5.0 and 7.5\% \% $/{ }_{\text {w }}$ of Hyptis suaveolens aerial extract

Figure 7. Globule size distribution for Hyptis suaveolens dermatological formulations.

\section{Photomicrographs of the formulations}

The Photomicrographs of the dermatological formulations are shown in Figure 8. The globules were seen to be spherical and the outer part took up the aqueous dye. The sphericity of the globules is generally a contributory factor to the stability of dispersed systems like creams. This could have assisted the cream formulation in maintaining stability shown when tested for 3 months. The uptake of the aqueous dye by the outer part of the globules leaving colourless internal part shows that the formulations had aqueous dispersion medium and the internal phase which could not be stained with the dye was the oil. This implies that the formulations were oil-in-water emulsions. Oil-in-water semi solid formulations are usually miscible with water, easily water-washable and readily rubs into the skin hence sometimes called vanishing cream ${ }^{21}$. Water washable creams are generally aesthetic and cosmetically acceptable compared to oily type ${ }^{22}$. The dermatological creams prepared in this study can therefore find application as vanishing cream in addition to therapeutic importance. 


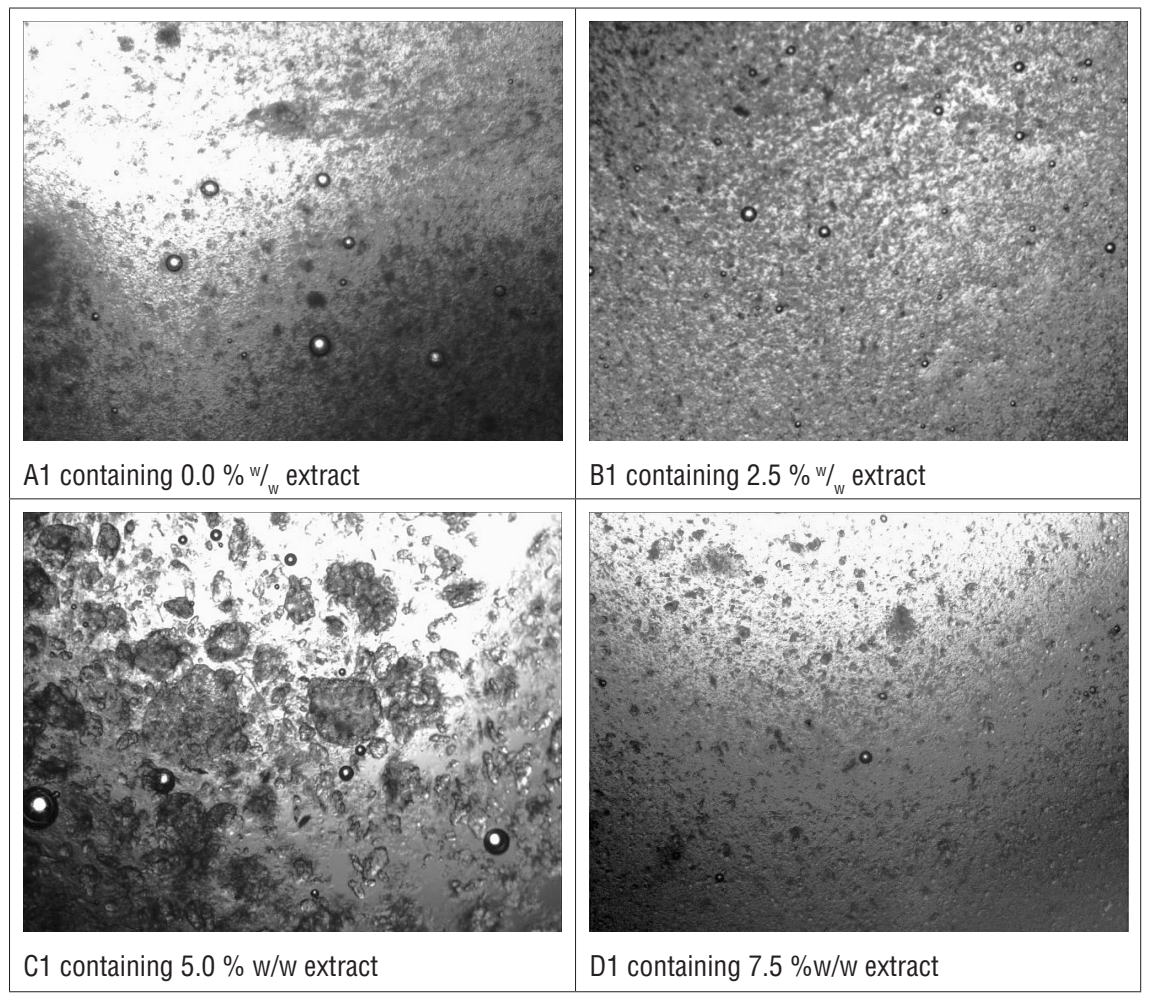

Figure 8. Photomicrographs of Hyptis suaveolens dermatological formulations showing dispersed globules

\section{Antimicrobial studies}

The results of the antibacterial activity of the dermatological formulations are presented in Table 4. The dermatological formulations of Hyptis suaveolens aerial extract showed antibacterial properties on both the clinical and standard isolates of Staphylococcus aureus (S. a). The activity was observed to be concentration dependent. While B1 containing $2.5 \% \mathrm{w} / \mathrm{w}$ of the extract showed no activity on the microorganisms, $\mathrm{C} 1$ and D1 containing 5 and $7.5 \% \mathrm{w} / \mathrm{w}$ of the extract had appreciable effect. All concentrations of $\mathrm{C} 1$ showed activity on the clinical strain of $S$. aureus while only $100 \mathrm{mg} / \mathrm{mL}$ and the undiluted form of $\mathrm{C} 1$ showed activity on the standard strain of the microorganism. This implies that the standard strain of $S$. aureus used in this study requires higher concentration to overcome its defences. Interestingly however, there were no significant differences ( $\mathrm{p}>0.05$ ) in the zone of inhibition of $100 \mathrm{mg} / \mathrm{mL}$ on the clinical and standard strains. In all cases, the undiluted cream gave higher zones of inhibition still showing a concentration-dependent response. 
Table 4. The effect of Hyptis suaveolens dermatological formulation on bacteria strains (mean $\pm \mathrm{SD}, \mathrm{n}=3$ )

\begin{tabular}{|c|c|c|c|c|}
\hline \multirow{2}{*}{$\begin{array}{c}\text { Formulation } \\
\text { code }\end{array}$} & $\begin{array}{c}\text { Cream } \\
\text { concentration } \\
(\mathbf{m g} / \mathbf{m L})\end{array}$ & $\begin{array}{c}\text { Staphylococcus } \\
\text { aureus } \\
\text { (clinical isolate) }\end{array}$ & $\begin{array}{c}\text { Staphylococcus } \\
\text { aureus (Standard } \\
\text { microorganism) }\end{array}$ & $\begin{array}{c}\text { Pseudomonas } \\
\text { aeruginosa } \\
\text { (standard } \\
\text { microorganism) }\end{array}$ \\
\cline { 2 - 5 } & \multicolumn{3}{|c|}{ Zone of inhibition (mm) } \\
\hline \multirow{4}{*}{ A1 } & 25 & 0.0 & 0.0 & 0.0 \\
& 50 & 0.0 & 0.0 & 0.0 \\
& 100 & 0.0 & 0.0 & 0.0 \\
& Undiluted (100 mg) & 0.0 & 0.0 & 0.0 \\
B1 & 25 & 0.0 & 0.0 & 0.0 \\
& 50 & 0.0 & 0.0 & 0.0 \\
& 100 & 0.0 & 0.0 & $12.3 \pm 1.2$ \\
C1 & Undiluted (100 mg) & 0.0 & 0.0 & $15.0 \pm 1.5$ \\
& 25 & $15.00 \pm 1.54$ & 0.0 & $10.0 \pm 2.4$ \\
& 50 & $17.30 \pm 1.33$ & 0.0 & $13.0 \pm 1.1$ \\
& 100 & $21.20 \pm 1.04$ & $20.50 \pm 2.72$ & $18.0 \pm 1.5$ \\
& Undiluted (100 mg) & $25.50 \pm 2.34$ & $27.00 \pm 1.23$ & $20.5 \pm 2.1$ \\
& 25 & $6.0 \pm 5.29$ & 0.0 & 0.00 \\
& 50 & $17.83 \pm 0.76$ & $15.0 \pm 0.0$ & $11.0 \pm 2.5$ \\
& 100 & $22.17 \pm 1.26$ & $23.5 \pm 1.04$ & $28.0 \pm 3.1$ \\
& Undiluted (100 mg) & $27.32 \pm 0.98$ & $33.0 \pm 2.3$ & $39.5 \pm 2.5$ \\
\hline
\end{tabular}

There was no activity on Pseudomonas aeruginosa clinical isolate hence not shown on the Table.

Reference cream used is Betamethasone-neomycin cream (Table 6).

Generally, dermatological formulations are used on application sites without dilution, except otherwise prescribed by the physician; it is understandable therefore that the undiluted showed higher inhibitory responses. Dilution was however done to observe what would happen when lower quantities are used by the patient. Lower amount of the cream formulation will definitely contain reduced quantity of the bioactive extract. None of the formulations showed activity on the clinical isolate of Pseudomonas aeruginosa while diluted $\mathrm{B} 1(100 \mathrm{mg} / \mathrm{mL})$ and undiluted showed activity on the standard strain in addition to formulations $\mathrm{C} 1$ and D1.

Comparing the activity of the cream formulations to the negative control (distilled water), it was observed that the formulations showed superior properties because the negative control showed no zone of inhibition. Furthermore, comparing the activity of the undiluted formulations to that of the positive control (Betamethasone-neomycin cream), which was also not diluted, the for- 
mulations demonstrated significantly improved $(\mathrm{p}<0.05)$ properties both for the clinical and standard isolates. However, the positive control showed activity against both clinical and standard microorganisms of Staphylococcus aureus and Pseudomonas aeruginosa. Formulation A1 is also a control (base) since it has $0.0 \% \mathrm{w} / \mathrm{w}$ of the extract and it showed no activity on all the microorganisms used. This showed that whatever activity is observed in the dermatological formulations may be attributed to the extract incorporated.

The antifungal activity of the dermatological formulations is presented in Table 5 . The results showed that all concentrations used were active although the undiluted was significantly higher $(\mathrm{p}<0.05)$. The activity of all the formulations on the fungal strains was also concentration-dependent within each formulation and among B1, C1 and D1. Comparing the activity of the formulations with that of the positive control (ketoconazole), the undiluted formulations demonstrated significantly $(\mathrm{p}<0.05)$ higher activity on both Candida albicans and Trychophyton rubrum (Table 6). This shows that the dermatological formulations of Hyptis suaveolens aerial extract can be further developed for antimicrobial application in dermatophytes infection.

Table 5. The effect of Hyptis suaveolens dermatological formulation on fungal strains $($ mean $\pm S D, n=3$ )

\begin{tabular}{|c|c|c|c|}
\hline \multirow{2}{*}{ Formulation code } & $\begin{array}{c}\text { Cream concentration } \\
(\mathbf{m g} / \mathbf{m L})\end{array}$ & \multicolumn{2}{|c|}{ Zone of inhibition $(\mathbf{m m})$} \\
\cline { 2 - 4 } & 25 & 0.00 & 0.00 \\
& 50 & 0.00 & 0.00 \\
& 100 & 0.00 & 0.00 \\
& Undiluted & 0.00 & 0.00 \\
& 25 & $10.00 \pm 1.25$ & $9.12 \pm 2.34$ \\
B1 & 50 & $14.37 \pm 1.24$ & $13.25 \pm 0.76$ \\
& 100 & $16.55 \pm 2.19$ & $16.50 \pm 0.57$ \\
& Undiluted & $22.58 \pm 2.34$ & $19.17 \pm 1.09$ \\
& 25 & $12.07 \pm 1.23$ & $10.35 \pm 0.87$ \\
C1 & 50 & $15.53 \pm 0.99$ & $13.00 \pm 1.25$ \\
& 100 & $20.75 \pm 2.13$ & $18.05 \pm 0.77$ \\
& Undiluted & $24.50 \pm 0.78$ & $24.17 \pm 1.22$ \\
& 25 & $15.59 \pm 1.05$ & $12.25 \pm 2.08$ \\
& 50 & $21.44 \pm 0.69$ & $22.50 \pm 1.23$ \\
& 100 & $23.15 \pm 0.89$ & $27.09 \pm 0.56$ \\
& Undiluted & $29.75 \pm 0.97$ & $33.50 \pm .2 .43$ \\
\hline
\end{tabular}

Reference cream used was ketoconazole cream (Table 6) 
Table 6. Activity of controls (positive and negative) on the microorganisms

\begin{tabular}{|c|c|c|c|c|c|c|}
\hline $\begin{array}{c}\text { Description } \\
\text { of control }\end{array}$ & $\begin{array}{c}\text { S. aureus } \\
\text { (clinical } \\
\text { isolate) }\end{array}$ & $\begin{array}{c}\text { S. aureus } \\
\text { (standard } \\
\text { microorganism) }\end{array}$ & $\begin{array}{c}\text { Pseudomonas } \\
\text { aeruginosa } \\
\text { (Clinical } \\
\text { isolate) }\end{array}$ & $\begin{array}{c}\text { Pseudomonas } \\
\text { aeruginosa } \\
\text { (standard } \\
\text { microorganism) }\end{array}$ & $\begin{array}{c}\text { Candida } \\
\text { albicans }\end{array}$ & $\begin{array}{c}\text { Trychophyton } \\
\text { rubrum }\end{array}$ \\
\hline \multicolumn{7}{|c|}{ Zone of inhibition (mm) } \\
\hline $\begin{array}{c}\text { Bethamethasone- } \\
\text { neomycin cream }\end{array}$ & $24.0 \pm 1.5$ & $14.50 \pm 1.25$ & $20.00 \pm 2.20$ & $12.50 \pm 1.50$ & NA & NA \\
\hline Ketoconazole cream & NA & NA & NA & NA & $18.35 \pm 2.50$ & $15.24 \pm 2.15$ \\
\hline Distilled water & 0.0 & 0.0 & 0.0 & 0.0 & 0.0 & 0.0 \\
\hline
\end{tabular}

$100 \mathrm{mg}$ of control was used undiluted and placed in the well.

The dermatological formulations of Hyptis suaveolens aerial extract were successfully prepared, they were oil-in-water emulsions, washable and cosmetically acceptable hence can find application as vanishing cream in addition to therapeutic importance. In addition, the $\mathrm{pH}$ of the formulated creams after exposure to different storage conditions had no significant change showing stability of the active ingredient in the base. The creams had high viscosity values indicating the adherent property to the skin surface after application. The fair to very high occlusion values showed that in addition to the therapeutic activity of these cream formulations, they will also help in preventing skin dryness, maintenance of skin smoothness and elasticity.

Formulation D1 will retain water more than the others and therefore maintain its physical outlook more and drying up will be prevented. The globule size distribution for all the formulations implied that the activity of the dermatological formulations will cut across the hair follicles, stratum corneum, follicular ducts and skin surface.

The activity of the formulations against bacterial clinical isolates was not as encouraging as that of the standard strains. The cream formulations especially at higher concentrations of 5.0 and $7.5 \% \mathrm{w} / \mathrm{w}$ exhibited significant antifungal activity against the tested microorganisms. Overall assessment indicates that the formulations have potential for development as a standardized dosage form for the applicable for the treatment of skin infections where the interrogated organisms are implicated. It could therefore be developed for commercial use.

\section{CONFLICT OF INTEREST}

The authors all agreed that there was no conflict of interest of whatsoever.

\section{ACKNOWLEDGEMENTS}

The authors are grateful to the technical staff of the department of Pharmaceutical Technology and Raw Materials Development, National Institute for Pharmaceutical Research and Development (NIPRD). 


\section{REFERENCES}

1. Austin, D. J.; Kristinson, K. G.; Anderson, R. M. The relationship between the volume of antimicrobial consumption in human communities and the frequency of resistance. PNAS. 1999, 96, 1152-1156.

2. Sharma, P. P.; Roy, R. K.; Anurag, D. G.; Sharma, V. K. Hyptis suaveolens (L.) poit. A phytopharmacological review. IJCPS. 2013, 4, 1-11.

3. Witayapan, N.; Sombat, C.; Siriporn, O. Antioxidant and Antimicrobial Activities of Hyptis suaveolens Essential Oil. Sci. Pharm. 2007, 75, 35-46.

4. Burkill, H. M. The useful plant of West Tropical Africa. RBG. 2005, 1, 481.

5. Abagli, A. Z.; Alavo, T. B. C. Essential oil from Bush Mint, Hyptis suaveolens is as effective as DEET for personal protection against mosquito bites. TOENJ. 2011, 5, 45-48.

6. Rolland, A. Site-Specific Drug Delivery to Pilosebaceous Structures Using Polymeric Microspheres. Pharm. Res. 1993, 10, 1738-1744.

7. Conti, B.; Benelli. G.; Flamini, G.; Cioni, P. L.; Profeti, R.; Ceccarini, L.; Macchia, M.; Canale, A. Larvicidal and repellent activity of Hyptis suaveolens essential oil against the mosquito Aedes albopictus skuse. Parasitol. Res. 2012, 11, 2013-2021.

8. Pino, J. A.; Marbot, R.; Payo, A.; Chao, D.; Herrera, P.; Marti, M. P. Leaf oil of Hyptis suaveolens from Cuba. JEOBP. 2003, 6, 120-126.

9. Ayange-kaa, A. B.; Hemen, T. J.; Onyezilli, N. The effect of dried leaves extract of Hyptis suaveolens on various stages of mosquito development in Benue State, Nigeria. IOSR-JPBS. 2015, $10,28-32$.

10. Wissing, S.; Lippacher, A.; Müller, R. Investigations on the occlusive properties of solid lipid nanoparticles (SLN). J. Cosmet. Sci. 2001, 52, 313-324.

11. Burkill, H.M. The useful plant of West Tropical Africa PART 2. RBG. 2005, 1, 481.

12. Aremu, O. I.; Femi, O.; Popoola, K. O. K. Repellent action of Neem seed oil cream against Anopheles gambiae mosquitoes. AFRREV. 2009, 3, 12-22.

13. Anita, G. Physical Properties of Emulsion Stabilized by k-casein before and after treatment with chymosin. A thesis submitted to the Office of Graduate Studies of Texas A \&M University, 2005 .

14. Schmid-Wendtner, M. H.; Korting, H. C. The PH of the skin surface and its impact on the barrier function. Skin. Pharmacol. Appl. Skin. Physiol. 2006, 19, 296-303.

15. Olotuah, O. F. Laboratory evaluation of pesticidal activities of Hyptis suaveolens in pest management. Int. J. Agric. Res. 2013, 8, 101-106.

16. Idson, B.; Lazarus, J. Semisolids. In: The theory and practice of industrial pharmacy, $3^{\text {rd }}$ ed.; Lachman L, Lieberman HA, Kanig JL., Eds.; Varghese Publishing House: Bombay,1991; pp 534- 563.

17. Adeyeye, M. C.; Jain, A. C.; Ghorab, M.; Reilly, W. J. Viscoelastic Evaluation of Topical creams containing Microcrystalline Cellulose/Sodium Carboxymethyl Cellulose as stabilizer. AAPS. Pharm. Sci. Tech. 2002, 3, 2.

18. Maru, A. D.; Lahoti, S. R. Formulation and Evaluation of moisturizing cream containing sunflower wax. Int. J. Pharm. Pharm. Sci. 2018, 10, 54-59.

19. Rolland, A. Site-Specific Drug Delivery to Pilosebaceous Structures Using Polymeric Microspheres. Pharm. Res. 1993, 10, 1738-1744. 
20. Barry, B. W. Transdermal Drug Delivery. In: Pharmaceutics; the Science of Dosage Form Design, $2^{\text {nd }}$ ed.; Aulton M.E., Ed.; London; Churchill Livingstone Publishing House: London, 1996; pp 269-270.

21. Flynn G. L. Cutaneous and Transdermal Delivery - Process and Systems of Delivery. In: Banker GS, Rhodes CT, editors. Modern Pharmaceutics. New York: Marcel Dekker, Inc; 2002; pp. $187-235$.

22. Reuter, J.; Merfort, I.; Schempp, C.M. Botanicals in dermatology: an evidence-based review. Am. J. Clin. 2010, 11, 247-267. 